\title{
Avian Information Systems: Developing Web-Based Bird Avoidance Models
}

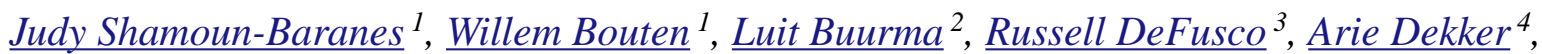 \\ $\underline{\text { Henk Sierdsema }}^{5}$, Floris Sluiter $^{1}, \underline{\text { Jelmer van Belle }}^{4}, \underline{\text { Hans van Gasteren }}^{4}{ }^{2}$, and Emiel van Loon ${ }^{1}$
}

\begin{abstract}
Collisions between aircraft and birds, so-called "bird strikes," can result in serious damage to aircraft and even in the loss of lives. Information about the distribution of birds in the air and on the ground can be used to reduce the risk of bird strikes and their impact on operations en route and in and around air fields. Although a wealth of bird distribution and density data is collected by numerous organizations, these data are not readily available nor interpretable by aviation. This paper presents two national efforts, one in the Netherlands and one in the United States, to develop bird avoidance nodels for aviation. These models integrate data and expert knowledge on bird distributions and migratory behavior to provide hazard maps in the form of GIS-enabled Web services. Both models are in operational use for flight planning and flight alteration and for airfield and airfield vicinity management. These models and their presentation on the Internet are examples of the type of service that would be very useful in other fields interested in species distribution and movement information, such as conservation, disease transmission and prevention, or assessment and mitigation of anthropogenic risks to nature. We expect that developments in cyber-technology, a transition toward an open source philosophy, and higher demand for accessible biological data will result in an increase in the number of biological information systems available on the Internet.
\end{abstract}

Key Words: birds; distribution; flight safety; migration; spatial modeling; web services.

\section{INTRODUCTION}

Close proximity between birds and aircraft can result in serious conflict. Birds can cause considerable damage and even the destruction of aircraft or the loss of lives. For example, it is estimated that bird strikes cost the United States Air Force U.S. \$33 million annually, including the loss of aircraft; the United Kingdom Royal Air Force U. S. \$22.3 million annually, excluding lost aircraft; and commercial airlines worldwide more than U.S. $\$ 1$ billion annually (Allan 2002). Between 1950 and 1999, 190 European military aircraft were destroyed because of collisions or attempts to avoid collisions with birds (Richardson and West 2000). To reduce the potential hazards birds cause aviation, civil and military aviation need reliable information about the density distributions and movements of birds in time and three-dimensioal space.
Bird strikes can be reduced in two ways: by avoiding birds or by reducing the number of birds in and around airfields via habitat management, active bird-scaring techniques, and even hunting. Military aviation can do both during training, whereas commercial aviation can generally only do the latter. In some countries, real-time or near real-time information on bird movements is already used for to make alterations in the flight trajectory of military aircraft, delay takeoff, or cancel flights. Information with a time scale of days or months can be used for flight planning, habitat management, spatial planning, and conservation mitigation. Clearly, information is needed at different scales in time and space to reduce the impact birds have on aviation en route and locally in and around airfields.

In many countries worldwide, geo-referenced presence-absence and abundance data are collected for numerous organisms. These data are often

\footnotetext{
${ }^{1}$ Universiteit van Amsterdam, ${ }^{2}$ Bird Strike Fund, ${ }^{3}$ BASH Inc., ${ }^{4}$ Royal Netherlands Air Force, ${ }^{5}$ SOVON, Dutch Centre for Field Ornithology
} 
collected by thousands of volunteers involved in various monitoring schemes representing a significant contribution of citizen science. These monitoring data have proven to be extremely valuable for spatiotemporal analyses, for example, to identify phenological changes indicating a response to climate change (e.g., Parmesan and Yohe 2003, Jonzen et al. 2006, Menzel et al. 2006), or population trends affected by environmental change (e.g., Krebs et al. 1999, Benton et al. 2002, Stuart et al. 2004). Observational data can provide essential information about densities and distributions of birds on the ground and to some extent even about birds in the air. In addition, during the last few decades, radar ornithology has provided information on birds in the air unobtainable from visual observations (e.g., Gauthreaux 1996 and references therein). Although a massive amount of data has been collected by many people, both professionals and volunteers, these data cannot be applied directly to reduce the risk birds pose to aircraft. The data must be processed and presented in such a way as to provide an indication of the relevant risk that birds may pose in different regions and during different times of the year.

This paper briefly describes two independently developed Web-based bird avoidance models (BAMs), the Netherlands BAM (NL-BAM)(https:// www.bambas.ecogrid.nl/) and the US-BAM covering the continental United States and Alaska ( http://www.usahas.com/bam/). Both systems provide fine-resolution and frequent predictions of bird densities in interactive GIS-enabled, user-friendly environments that are available on the Internet. In addition, the NL-BAM has a dynamic module for migration predictions. The development of these models has required a transdisciplinary approach including expertise in field and radar ornithology, geostatistics, computational modeling, information management, GIS, remote sensing, computer sciences, and cooperation between military, academic, commercial, and nature conservation institutes, including the contribution of citizen science. Finally, we discuss future perspectives to improve these BAMs and how avian information systems may be applicable to broader ecological communities.

\section{METHODS}

\section{From field observations to spatiotemporal density distribution maps}

Both bird observation models (BAMs) provide predictions of the density in numbers and mass $/ \mathrm{km}^{2}$ or mass $/ \mathrm{km}^{3}$, biweekly (26 time frames/yr, USBAM) or twice a month (24 time frames/yr, NLBAM), 4 periods/d for a number of key species or species groups (62 for the NL-BAM, 71 for the USBAM). Field observation data were collected from various sources, mainly from the Dutch Centre for Field Ornithology (SOVON), the U.S. Geological Survey, and the U.S. Fish and Wildlife Service. The density of birds was modeled to develop density distribution maps to fill temporal and spatial gaps in the observational data. Information about the diurnal activity patterns of birds, seasonal abundance, the relative amounts of birds in the air, and other essential information were stored in relational databases to facilitate easy access, management, quality assurance, and integration with models. The additional biological information needed to develop both models was collected from the literature, expert knowledge from field ornithologists, and bird strike databases (Dolbeer et al. 2000, Dekker et al. 2003, Zakrajsek and Bissonette 2005).

For the NL-BAM, regression kriging (Odeh et al. 1995, Hengl et al. 2004) was used to model the spatial distribution of each of the 62 species in relation to environmental factors such as soil type, land use, and water bodies. When applying a species distribution model (SDM) to our bird observations, we often observed that the residuals, i.e., the differences between model predictions and measurements, were spatially correlated. Therefore we used a geostatistical model to describe the residuals and added its prediction to the SDM predictions. As seen in step 1 of Fig. 1, the observed counts for the NL-BAM were first related to environmental variables via general additive regression models (GAMs). GAMs are able to describe nonlinear relationships between the environmental factors and the number of birds and are a frequently used SDM (Elith et al. 2006). Second, we described the spatial correlation in the residuals with a correlation function, the functional form of which may be different for each GAM and is identified manually, and interpolated the residuals to the regular grid of the GAM by universal kriging (step 2, Fig. 1). We then added the kriging 
Fig. 1. A diagram of the Netherlands bird avoidance model (NL-BAM) workflow describing the modeling and processing procedures used to produce the NL-BAM maps. Central boxes represent the processing steps described in the text and in Table 1. Boxes with dashed lines represent processing steps that were repeated for each type of survey data. For example, for the buzzard, a separate general additive model was fit to the breeding bird survey as well as each of the four nonbreeding point surveys. Boxes shaded in grey represent supporting information needed to perform specific tasks.

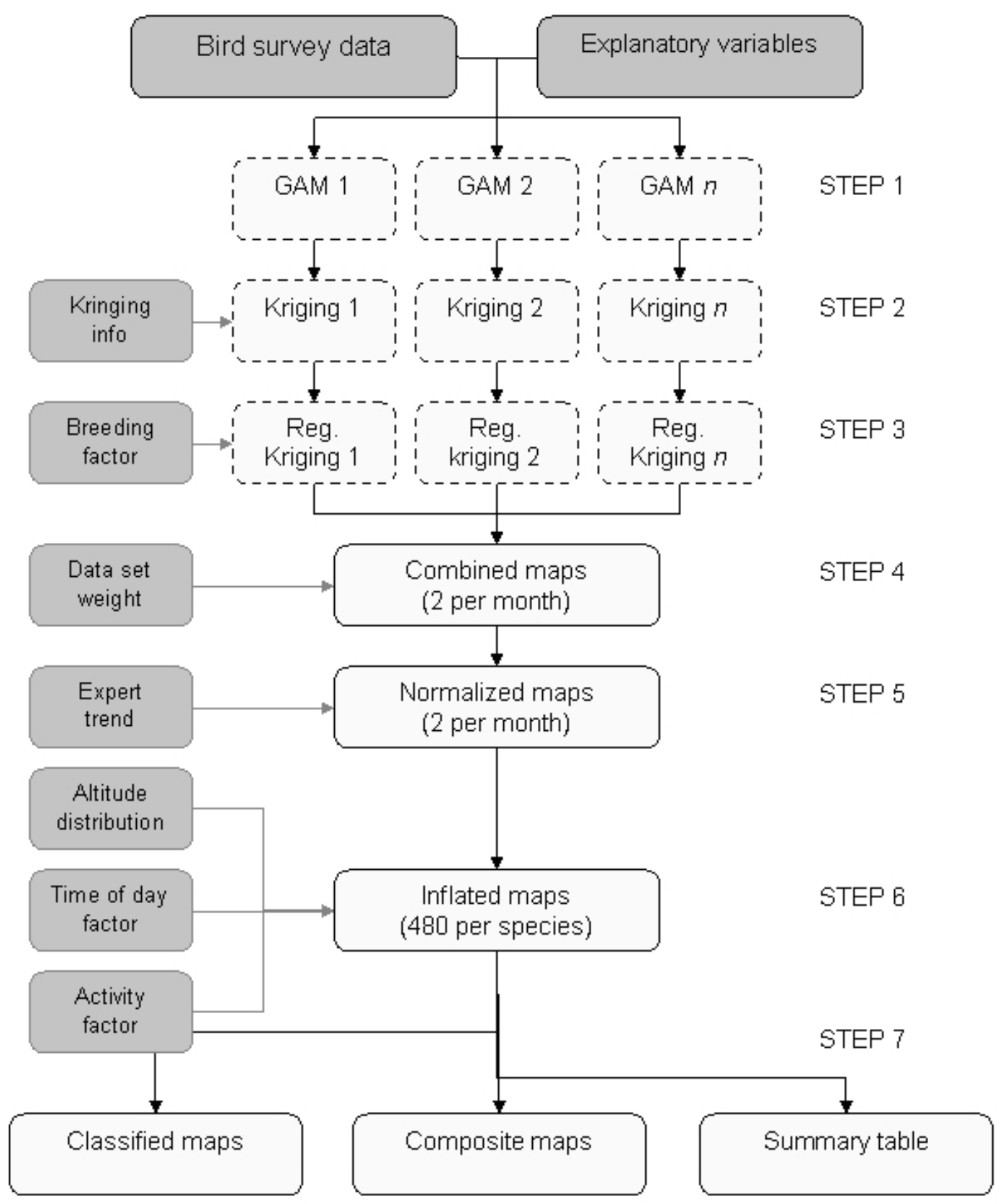


Fig. 2. (A) The number of common buzzards (Buteo buteo) observed per nonbreeding bird survey site in December 2000. The larger and darker the circle, the more birds per survey site. (B) The modeled buzzard density distribution, i.e., number of birds per $\mathrm{km}^{2}$. The modeled distribution was created using regression-kriging, further described in the methods section (see also Fig. 1 and steps 1-3 in Table 1).
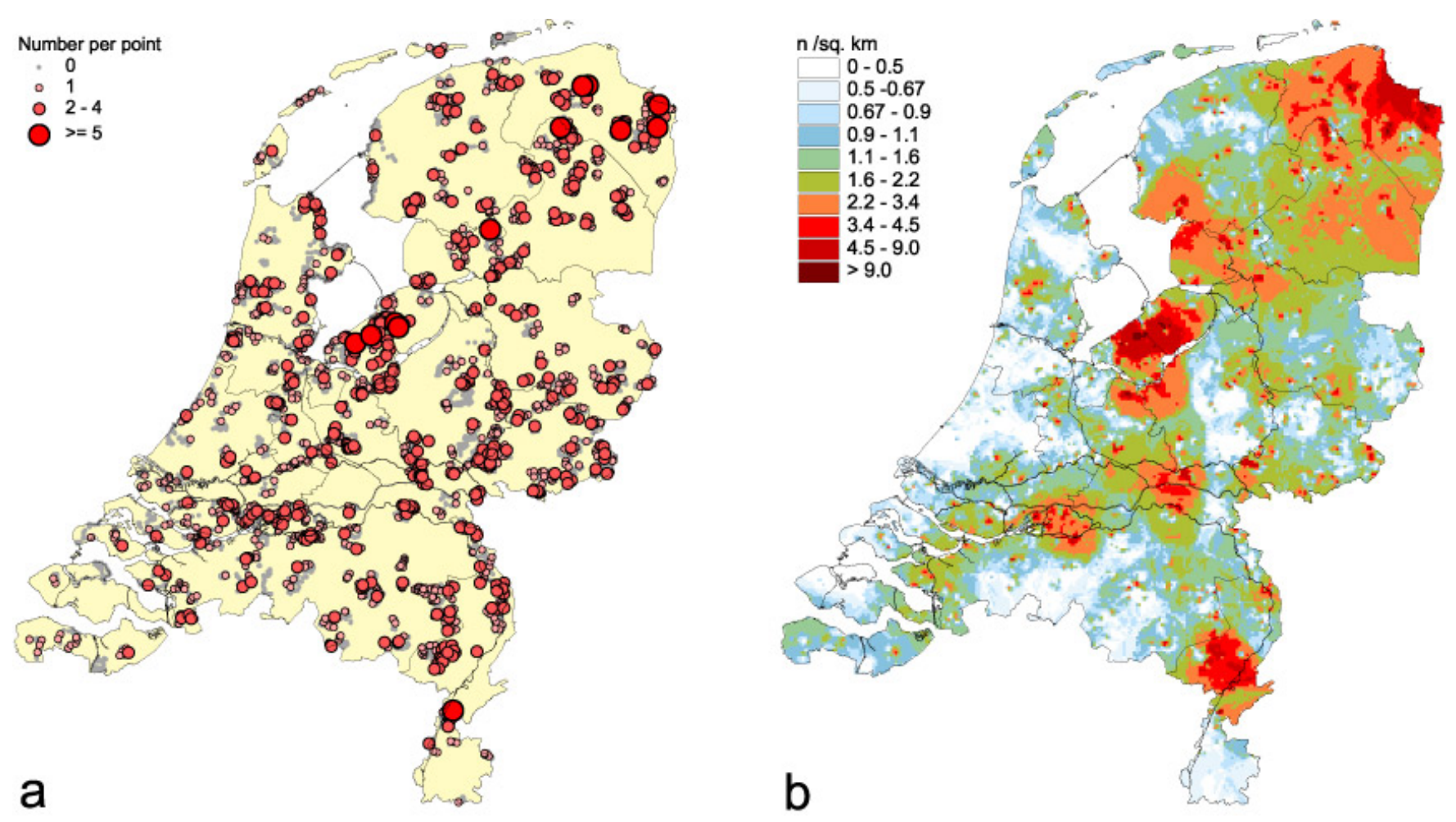

predictions to the GAM predictions (step 3, Fig. 1). This results in maps that make optimal use of the relationships between environmental predictors and the information in the individual counts (Fig. 2). Predicted flight altitude distribution of birds was integrated into the NL-BAM based on dedicated bird-radar measurements (Shamoun-Baranes et al. 2006), bird strike data (Dekker et al. 2003), the literature, and expert knowledge. Information on seasonal trends in abundance was collected from weekly counts on air fields, monthly wetland counts, and the literature.

Because of the complexity of integrating different data sources, a modeling workflow was designed (Fig. 1). All expert knowledge and observational data used in this workflow were stored in a database. In this way the workflow streamlined the entire modeling procedure, ensured the replicability of the results, and made it possible to update the output maps when data and expert knowledge change. The modeling workflow shown in Fig. 1 is described in detail in Table 1 for a single species, the common buzzard (Buteo buteo); more detailed information on the modeling techniques can be found in Shamoun-Baranes et al. (2005).

One of the special features of the NL-BAM is the inclusion of both species-specific maps and composite density maps. In total, 31,680 speciesspecific maps and 960 composite maps were created and are presented on the NL-BAM Web site. A regional summary table of the 10 most abundant species in the air provides the total number of birds in the air and is hyperlinked to the respective species-specific maps (Fig. 3). 
Table 1. A description of the Netherlands bird avoidance model workflow (Fig. 1) presented for a single species, the common buzzard (Buteo buteo). GAM stands for general additive regression model, and BAM for bird avoidance model.

Step 1

GAM

Step 2

Kriging

Step 3

Regression-kriging

Step 4

Combined maps

Step 5

Normalized maps

Step 6

Inflated maps

Step 7

\begin{abstract}
The relationship between the counts on samples sites and environmental variables is described using a GAM. A separate GAM is developed for each survey and applied at a resolution of $1 \mathrm{~km}^{2}$, covering the entire Netherlands. For the buzzard, counts are available from five surveys: one breeding bird survey and four point counts of nonbreeding birds throughout the year (Fig. 2A), resulting in five different GAMs and five different maps.
\end{abstract}

To account for spatial correlation in the residuals, the residuals for each GAM are spatially interpolated using universal kriging.

The spatially interpolated residuals are added to the respective GAMs creating regressionkriging distribution maps (Fig. 2B). In this step, a breeding factor is used to convert counts of breeding pairs to numbers of individuals.

This step combines the different regression-kriging models to estimate the spatial distribution of each species twice a month. For different groups of birds, different count data are available. For example, for some species, only the breeding bird counts and the nonbreeding bird counts are available; for other species, monthly waterbird counts are available as well. Each regression-kriging map is assigned a weight (data set weight) based on proximity of the survey period to the BAM period (weight diminishes with time). Subsequently, linear interpolation is applied to produce predictive maps for those BAM periods for which no surveys are assigned.

To prevent abrupt changes from one BAM period to another because of differences between the various data sets, the combined maps were smoothed with known seasonal trends. The smoothing procedure was as follows. Total abundance over the Netherlands, on the basis of the combined maps for each species and each BAM period, was normalized to range between 0 and 1; we call this the "model_trend." We used the known seasonal trends (the expert_trend) to correct the model trend via the following equation: $N M_{\mathrm{i}, \mathrm{t}}=C M_{\mathrm{i}, \mathrm{t}} *($ model_trend $+($ model_trend - expert_trend $) *$ expert_weight $)$ where $C M_{\mathrm{i}, \mathrm{t}}^{\mathrm{i}, \mathrm{s}}$ stands for Combined Map for bird $i$ in BAM period $t, N M_{\mathrm{i}, \mathrm{t}}$ stands for Normalized Map for bird species $i$ in BAM period $t$, and expert_weight is the degree to which expert_trend can correct model_trend (for most birds, expert_weight is set to 0.5).

For each bird species, the altitude distributions and activity patterns were derived for the four periods of day (morning, afternoon, dusk, dawn). Maps of the number of birds in the air are created for each combination of BAM period, time of day, and altitude, producing 480 predictive maps/species ( 24 periods a year x 4 times a day x 5 flight altitude layers).

Classified maps: Each map was classified into eight equal interval classes of birds $/ \mathrm{km}^{2}$. Composite maps: Maps of all species were combined to create maps of total number of birds $/ \mathrm{km}^{2}$ and total mass $/ \mathrm{km}^{2}$. Summary table: The sum of birds was calculated for three regions/time of year, time of day, and altitude layer, for the top 10 most abundant species.
For the US-BAM, data on bird distribution and abundance were obtained from many sources including federal, state, and private agencies. Data for those species considered potentially hazardous to aircraft operations were pooled to form species groups. Data on the temporal distribution of birds were obtained from a variety of sources including but not limited to wildlife refuges. The combined data formed an incomplete coverage of the United
States, with gaps between sampled sites to be filled by interpolation methods. The US-BAM risk surfaces are interpolated using a standard inverse distance-weighted interpolation protocol using the 12 nearest neighboring points and a squared decay function. After the raw normalized risk surface was derived for each 2-wk period of the year, daily activity patterns were added based on field observations, a literature review, and expert input 
Fig. 3. Screenshots from the spatial distribution module of the Netherlands bird avoidance model. Upper screenshot is of birds $/ \mathrm{km}^{2}$ at different altitudes from 1-15 March during dawn. The lower screen shot is the distribution of black-headed gulls (Larus ridibundus) in the air, one of the most abundant species during this time of day and year.

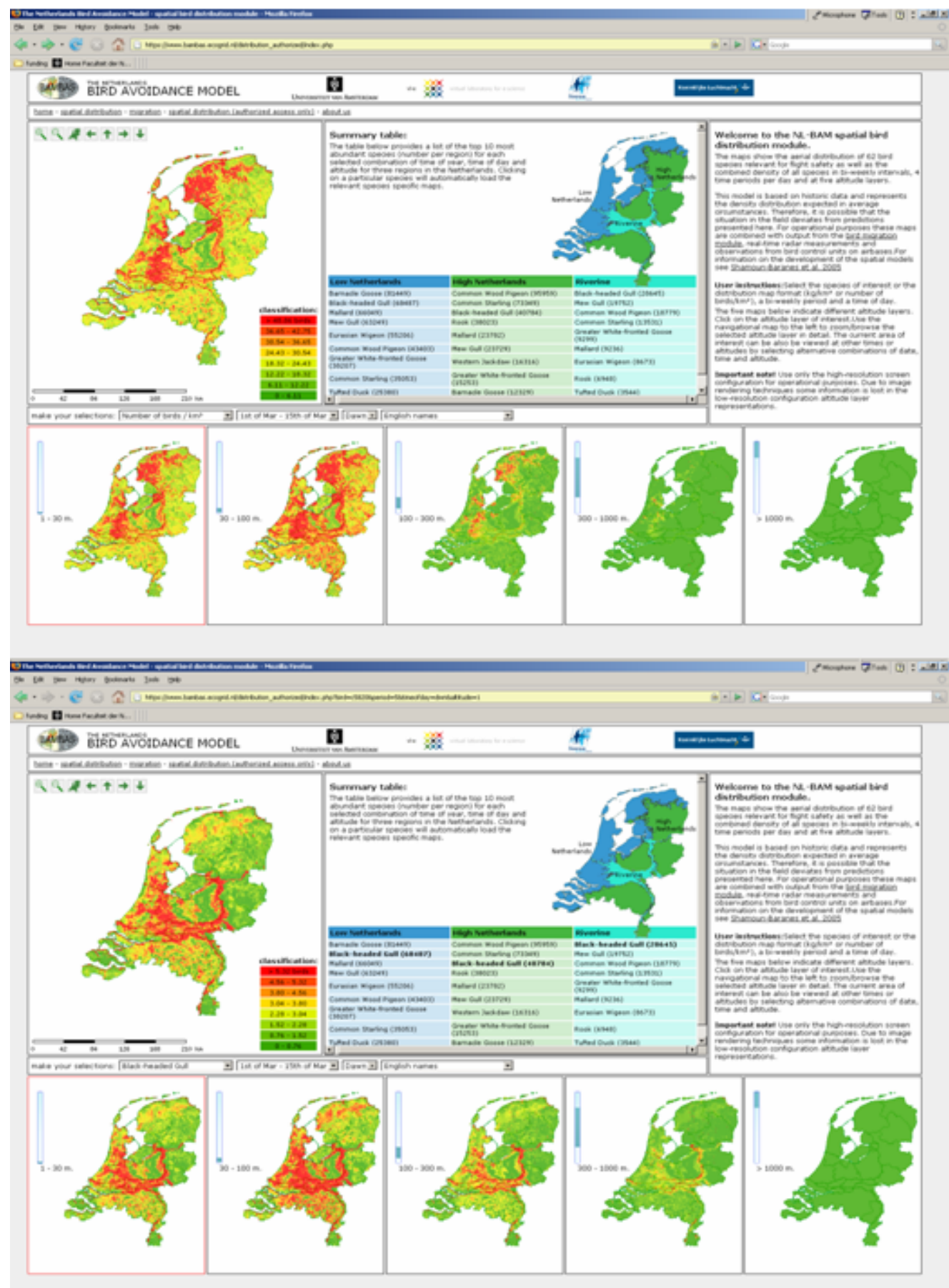


to develop four daily time-period risk maps during each 2-wk time frame (DeFusco et al. 2005). In the Alaska module, behavioral aspects were added to depict percentages of birds expected in the air during each of these periods. Further analyses were conducted by evaluating the presence of birds from numerous sample sites and correlating these data to the terrain and habitat present at those sites. Masking algorithms were applied to limit or eliminate predicted distribution and abundance of birds from environments in which suitable habitat was absent. These algorithms were applied to the raw risk surfaces to produce the final risk surfaces (Fig. 4). These surfaces were then classified to depict relative risk polygons.

\section{Migration predictions}

In several countries, e.g., the Netherlands, Germany, Belgium, Israel, and the USA, radar is used operationally by military aviation to monitor bird migration and to provide real-time bird migration warnings to air crews. However, radar monitoring alone does not make it possible to forecast migration intensity, information that is needed for short-term planning and rescheduling of military training flights. Without the development and application of models, the collected data can only be extrapolated to future times by expert judgment. Therefore, radar measurements of bird migration and meteorological data were used to develop and calibrate models predicting migration intensity in the Netherlands. Models were designed using different techniques including multiple regression analysis (Van Belle et al. 2007), artificial neural networks, and concept-based models (Bouten et al. 2005). The predictive variables included in the operational model are seasonal migration trend, preferential winds, 24-h change in barometric pressure, and precipitation. The migration module of the NL-BAM uses daily updated meteorological forecast data as input (wW w.arl.noaa.gov/ready/cmet) and provides a threeday forecast of the intensity of broad front migration over the Netherlands during the day and at night.

The US-BAM does not have a separate component that forecasts migratory movements in relation to weather. However, the US-BAM is linked to the Avian Hazard Advisory System, which provides near real-time warnings of migration "hot spots" as well as a 24-h forecast based on the WSR-88D
(Weather Surveillance Radar 88 Doppler) network and other remote sensing measurements (Kelly 2002; http://www.usahas.com/).

\section{Target users}

The avian information provided in the BAMs must be efficiently disseminated for it to be effectively applied. Therefore, several measures were taken to ensure that these BAMs would be integrated into operations. In the United States, staff members were provided with training programs. In the Netherlands, the user interface and model presentation was designed through an iterative process together with the users.

The NL-BAM has been in operational use since January 2006 and is currently used as a decision support tool by the ecology unit in the Royal Netherlands Air Force. The spatial distribution and migration modules are used differently. The spatial distribution models, which are based on historic data, are used for bird strike prevention in and around airfields. Information from these models is used to help formulate guidelines for airport bird control units and review spatial planning in the airport vicinity. During the migration season, the dynamic migration models are run every morning to generate a three-day forecast and are used in daily operations to reduce the risk and operational impact of en route bird strikes. The migration predictions and real-time radar observations form the basis for warnings to pilots (e.g., https://www.notams.jcs.mil/ common/birdtam.html) and for short-term flight planning. These predictions greatly reduce the impact migration has on operations. For example, in the past, night training missions were cancelled after sunset once migration was measured by the radar. Such last-minute cancellations are extremely costly, because all personnel and equipment are ready for training. Now migration model forecasts are used to cancel operations several hours in advance.

Different versions of the US-BAM have been in operation for more than $20 \mathrm{yr}$, with continuous upgrades to the system. The first Web-based USBAM with GIS functionality became operational in 1998. The US-BAM is used by a broad spectrum of military and civil users including pilots, flight schedulers, and airspace planners. All U.S. Air Force pilots are required to consult the BAMs and Avian Hazard Advisory System (AHAS) when 
Fig. 4. A sample bird strike risk map for Alaska from the United States bird avoidance model during the period 7-20 May, during daytime.

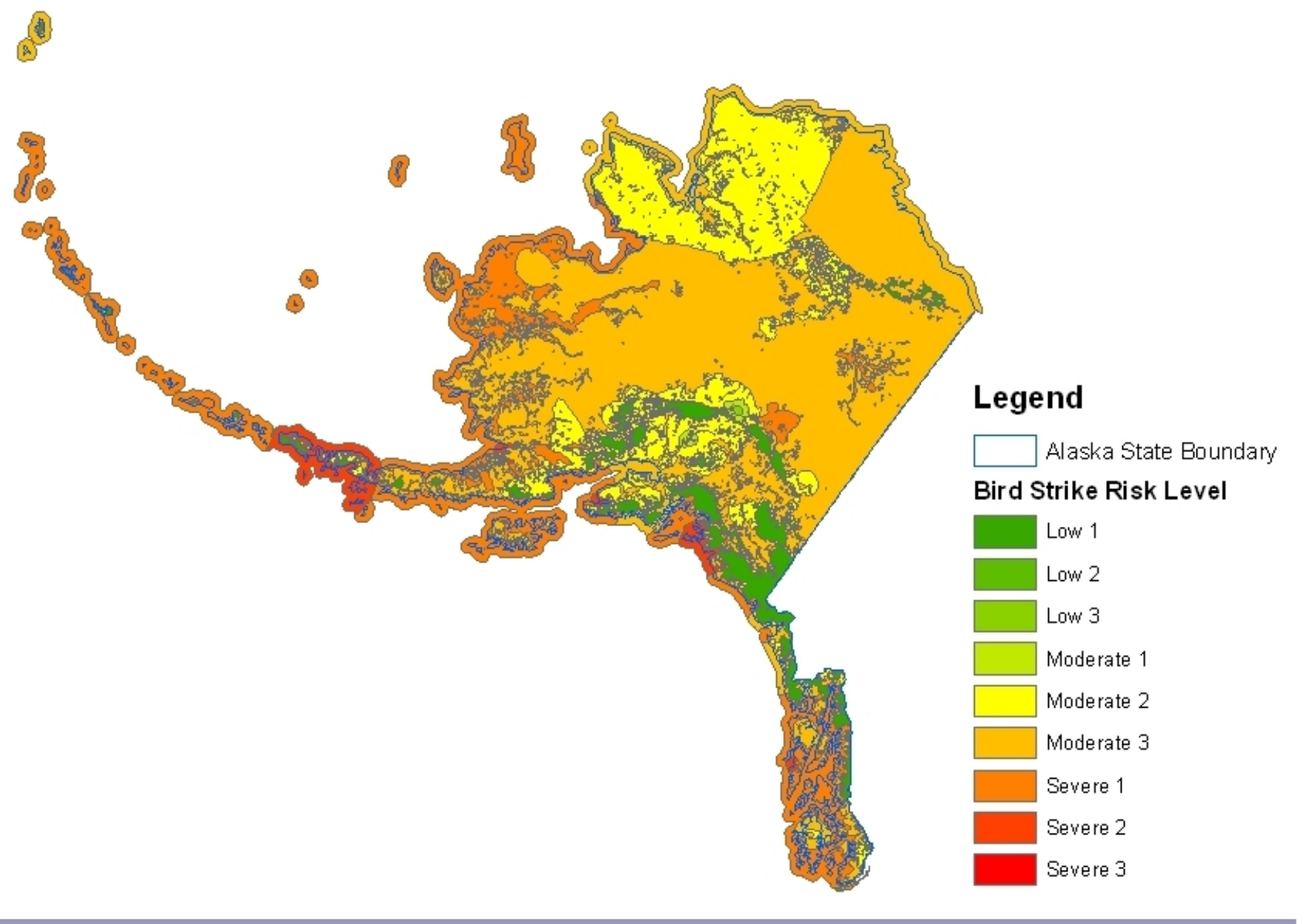

operating on low-altitude missions within the area of model coverage. Pilots are trained in the use of the models during Air Force Pilot Training with refresher briefings on the systems throughout their flying assignments. All air force flight safety officers and flight supervisors are also periodically trained in the use of and updates to the models so that they can pass the information to pilots in their flight squadrons. Airfield management personnel are also trained in the use of the models during their initial certification courses and are periodically retrained during their continuing education requirements. Training sessions on the US-BAM and AHAS system are also conducted during all assistance visits from headquarters-level flight safety staff to ensure the currency and appropriate application of the models. Training modules are available to all levels of users and are posted online on the BAM/AHAS Web site.

\section{Technical aspects of the Web services}

In the spirit of open-access philosophy, which is gaining momentum in many scientific communities (Doyle et al. 2004, Chan and Costa 2005, Engelward and Roberts 2007), the various organizations involved in developing the models made the decision to provide the output of the BAMs freely available on the Internet. It is the hope of the developers that this culture continues to spread and that international collaborations will form to expand these models. 
Because of the spatial nature of the density distribution models, both systems are GIS enabled, providing electronic cartographic capabilities such as zooming, panning, and the selection of particular features as overlays on the relative risk surfaces (US-BAM only). The NL-BAM uses UMN/ MapServer open source software (http://mapserver. gis.umn.edu/) to facilitate the visualization and access of hazard maps stored in postgreSQL (http:/ /www.postgresql.org/), an open-source spatial database. The US-BAM uses arcIMS (ESRI) to access maps stored in Access (Microsoft).

\section{FUTURE PERSPECTIVES}

Bird populations are constantly changing in response to various anthropogenic as well as natural factors. We estimate the longevity of the predictions by the bird avoidance models (BAMs) to be in the order of 5-10 yr. Therefore, a model update is recommended approximately once every $5 \mathrm{yr}$.

Beyond this model adjustment and maintenance we envision that a new generation of BAMs will develop both on larger multinational scales and on small scales for local airfields. New data will become available as animal tracking systems continue to advance, providing higher quality and quantities of data, which are essential to increase our understanding of bird movements. This knowledge can then be used to improve model performance. For example, improvements in biotelemetry and the continuous miniaturization of individual transmitters (Cooke et al. 2004, Wikelski et al. 2007) will provide more detailed information at the species level on flight speeds, altitudes, routes, time budgets, and habitat selection. Detailed data on bird movements can be particularly beneficial for modeling foraging and roosting flight routes, which are currently not included in either of the BAMs described in this paper. The increased availability of mobile radar units adapted for studying bird movements (Gauthreaux and Belser 2003, Huppop et al. 2006) can provide another source of movement data, both for modeling and for near real-time operations, either to mobilize bird control units or warn pilots in and around airfields. Furthermore, in Europe, the potential exists to collect information on migration flight altitudes from more than 150 weather radars in Europe via the OPERA (Operational Programme for the Exchange of weather RAdar information) network to improve the altitude component of the migration models (Gasteren et al., in press). Because of the continuous development in computer technology, huge quantities of data will become more easily accessible for processing and analysis and real-time transfer via the Internet or GRID. This is made possible not only by the mere availability of raw observations but especially by advances in tools to annotate, homogenize, and interpret the observations, e.g., tools for spatial modeling (Phillips et al. 2006, Rangel et al. 2006), automated georeferencing (Guralnick et al. 2006), and metadata storage and organization (Kareiva 2001, Fegraus et al. 2005). Therefore, in the future we hope to develop a bird avoidance system whose ensemble forecasts provide both enhanced predictions and a faithful representation of predictive uncertainty. In such a system, the models are continuously updated with radar measurements by applying data assimilation techniques.

Historically, civil aviation has been rather apprehensive of bird avoidance models as well as real-time warning systems. However, as these systems continue to develop and improve, they may even be integrated into safety management systems for civil air traffic control (Buurma 2007).

Web-based ecological information systems are quickly emerging and evolving (Bisby 2000, Zhang and Grassle 2002). Intuitive visualization of information about the distribution, abundance, and/ or movements of fauna and flora presented through these or similar systems such as the BAMs would be extremely useful for conservation advocacy, environmental planning, mapping the risk of zoonosis outbreak and spread, and education. For example, a mapping system that integrates the density and distribution of animals, their movement patterns, and relevant environmental information would greatly facilitate the identification of potential source and spread of vector-borne diseases such as avian influenza (Normile 2005, Kilpatrick et al. 2006, Yasue et al. 2006, Moffett et al. 2007, Xiao et al. 2007). In short, using the cyber infrastructure and new analytical and modeling tools, major advances can be made in ecological information systems with improved access to and integration of data from biological surveys, radar networks, animal tracking systems, and supporting, e.g., environmental, social, and economic, information collected by a multitude of conservation organizations, research institutes, and international organizations such as FAO and WHO. 
Responses to this article can be read online at:

http://www.ecologyandsociety.org/voll3/iss2/art38/responses/

\section{Acknowledgments:}

The Dutch Ministry of Defence through the Royal Netherlands Air Force (NL-BAM), United States Air Force, United States Air National Guard, and the U.S. Federal Aviation Administration contributed financially and/or through labor and material support to the development of the bird avoidance models described here. The NL-BAM was developed in the context of the Virtual Laboratory for e-Science project supported by a BSIK grant from the Dutch Ministry of Education, Culture and Science $(O C \& W)$ and is part of the ICT innovation program of the Ministry of Economic Affairs (EZ). We also thank the International Bird Strike Committee, Bird Avoidance Modelling Working Group, for fruitful discussions. This work couldn't have been done without the hard work of many people involved in collecting data.

\section{LITERATURE CITED}

Allan, J. R. 2002. The costs of bird strikes and bird strike prevention. Pages 147-153 in L. Clark, editor. Human conflicts with wildlife: economic considerations. National Wildlife Research Center, Fort Collins, Colorado, USA.

Benton, T. G., D. M. Bryant, L. Cole, and H. Q. P. Crick. 2002. Linking agricultural practice to insect and bird populations: a historical study over three decades. Journal of Applied Ecology 39:673-687.

Bisby, F.A. 2000. The quiet revolution: biodiversity informatics and the Internet. Science 289:2309-2312.

Bouten, W., J. van Belle, H. van Gasteren, J. A. Vrugt, J. Shamoun-Baranes, and L. Buurma. 2005. Predicting bird migration: data-driven versus concept-driven models. Pages 231-240. 27th International Bird Strike Committee, Athens, Greece.

Buurma, L. 2007. Bird strike prevention: SMS challenge and a green signal. International Airport Review (4):40-43.
Chan, L., and S. Costa. 2005. Participation in the global knowledge commons: challenges and opportunities for research dissemination in developing countries. New Library World 106:141-163.

Cooke, S. J., S. G. Hinch, M. Wikelski, R. D. Andrews, L. J. Kuchel, T. G. Wolcott, and P. J. Butler. 2004. Biotelemetry: a mechanistic approach to ecology. Trends in Ecology and Evolution 19:334-343.

DeFusco, R., J. T. Harper, and W. Ruhe. 2005. Alaska bird avoidance model (AK BAM) development and implementation. Available online at: http://www.int-birdstrike.org/Athens Papers/IBSC27\% 20WPI-4.pdf.

Dekker, A., H. van Gasteren, and J. ShamounBaranes. 2003. EURBASE, progress report and first impressions on bird species. Available online at: http://www.int-birdstrike.org/Warsaw Papers/ IBSC26\%20WPID2.pdf.

Dolbeer, R. A., S. E. Wright, and E. C. Cleary. 2000. Ranking the hazard level of wildlife species to aviation. Wildlife Society Bulletin 28:372-378.

Doyle, H., A. Gass, and R. Kennison. 2004. Open access and scientific societies. PLoS Biology 2: e156.

Elith, J., C. H. Graham, R. P. Anderson, M. Dudik, S. Ferrier, A. Guisan, R. J. Hijmans, F. Huettmann, J. R. Leathwick, A. Lehmann, J. Li, L. G. Lohmann, B. A. Loiselle, G. Manion, C. Moritz, M. Nakamura, Y. Nakazawa, J. McC. M. Overton, A. Townsend Peterson, S. J. Phillips, K. Richardson, R. Scachetti-Pereira, R. E. Schapire, J. Soberon, S. Williams, M. S. Wisz, and N. E. Zimmermann. 2006. Novel methods improve prediction of species' distributions from occurrence data. Ecography 29:129-151.

Engelward, B. P., and R. J. Roberts. 2007. Open access to research is in the public interest. PLoS Biology 5:e48.

Fegraus, E. H., S. Andelman, M. B. Jones, and M. Schildhauer. 2005. Maximizing the value of ecological data with structured metadata: an introduction to ecological metadata language (EML) and principles for metadata creation. Bulletin of the Ecological Society of America 86: $158-168$. 
Gasteren, H. V., I. Holleman, W. Bouten, E. V. Loon, and J. Shamoun-Baranes. 2008. Extracting bird migration information from C-band Doppler weather radars. Ibis 150, in press.

Gauthreaux, S. A. 1996. Bird migration: methodologies and major research trajectories (1945-1995). Condor 98:442-453.

Gauthreaux, S. A., and C. G. Belser. 2003. Radar ornithology and biological conservation. The Auk 120:266-277.

Guralnick, R. P., J. Wieczorek, R. Beaman, and R. J. Hijmans. 2006. BioGeomancer: automated georeferencing to map the world's biodiversity data. PLoS Biology 4:e381.

Hengl, T., G. B. M. Heuvelink, and A. Stein. 2004. A generic framework for spatial prediction of soil variables based on regression-kriging. Geoderma 120:75-93.

Huppop, O., J. Dierschke, K.-M. Exo, E. Fredrich, and R. Hill. 2006. Bird migration studies and potential collision risk with offshore wind turbines. Ibis 148:90-109.

Jonzen, N., A. Linden, T. Ergon, E. Knudsen, J. O. Vik, D. Rubolini, D. Piacentini, C. Brinch, F. Spina, L. Karlsson, M. Stervander, A.Andersson, J. Waldenstrom, A. Lehikoinen, E. Edvardsen, R. Solvang, and N. C. Stenseth. 2006. Rapid advance of spring arrival dates in long-distance migratory birds. Science 312:1959-1961.

Kareiva, P. 2001. Ecoinformatics: facilitating access to existing data sets. Trends in Ecology and Evolution 16:226.

Kelly, T. A. 2002. Managing birdstrike risk with the Avian Hazard Advisory System. Flying Safety $\mathbf{5 8}$ (9):18-21.

Kilpatrick, A. M., A. A. Chmura, D. W. Gibbons, R. C. Fleischer, P. P. Marra, and P. Daszak. 2006. From the cover: predicting the global spread of H5N1 avian influenza. Proceedings of the National Academy of Sciences 103:19368-19373.

Krebs, J. R., J. D. Wilson, R. B. Bradbury, and G. M. Siriwardena. 1999. The second silent spring? Nature 400:611-612.
Menzel, A., T. H. Sparks, N. Estrella, and D. B. Roy. 2006. Altered geographic and temporal variability in phenology in response to climate change. Global Ecology and Biogeography 15:498-504.

Moffett, A., N. Shackelford, and S. Sarkar. 2007. Malaria in Africa: vector species' niche models and relative risk maps. PLoS ONE 2:e824.

Normile, D. 2005. News focus: are wild birds to blame? Science 310:426-428.

Odeh, I. O. A., A. B. McBratney, and D. J. Chittleborough. 1995. Further results on prediction of soil properties from terrain attributes: heterotopic cokriging and regression-kriging. Geoderma 67:215-226.

Parmesan, C., and G. Yohe. 2003. A globally coherent fingerprint of climate change impacts across natural systems. Nature 421:37-42.

Phillips, S. J., R. P.Anderson, and R. E. Schapire. 2006. Maximum entropy modeling of species geographic distributions. Ecological Modelling 190:231.

Rangel, T. F. L. V. B., J. A. F. Diniz-Filho, and L. M. Bini. 2006. Towards an integrated computational tool for spatial analysis in macroecology and biogeography. Global Ecology and Biogeography 15:321-327.

Richardson, W. J., and T. West. 2000. Serious birdstrike accidents to military aircraft: updated list and summary. Available online at: http://www.int-b irdstrike.org/Amsterdam Papers/IBSC25\%20WPSA1. pdf.

Shamoun-Baranes, J., H. Sierdsema, E. van Loon, H. van Gasteren, W. Bouten, and F. Sluiter. 2005. Linking horizontal and vertical models to predict 3D + time distributions of bird densities. Available online at: http://www.int-birdstrike.org/A thens Papers/IBSC27\%20WPIX-3.pdf.

Shamoun-Baranes, J., E. van Loon, H. van Gasteren, J. van Belle, W. Bouten, and $L$. Buurma. 2006. A comparitive analysis of the influence of weather on the flight altitudes of birds. Bulletin of the American Meteorological Society 87:47-61. 
Stuart, S. N., J. S. Chanson, N. A. Cox, B. E. Young, A. S. L. Rodrigues, D. L. Fischman, and R. W. Waller. 2004. Status and trends of amphibian declines and extinctions worldwide. Science 306:1783-1786.

Van Belle, J., J. Shamoun-Baranes, E. Van Loon, and W. Bouten. 2007. An operational model predicting autumn bird migration intensities for flight safety. Journal of Applied Ecology 44:864-874.

Wikelski, M., R. W. Kays, N. J. Kasdin, K. Thorup, J.A.Smith, and G. W.Swenson, Jr. 2007. Going wild: what a global small-animal tracking system could do for experimental biologists. Journal of Experimental Biology 210:181-186.

Xiao, X., M. Gilbert, J. Slingenbergh, F. Lei, and S. Boles. 2007. Remote sensing, ecological variables, and wild bird migration related to outbreaks of highly pathogenic H5N1 Avian Influenza. Journal of Wildlife Disease 43:S40-46.

Yasue, M., C. J. Feare, L. Bennun, and W. Fiedler. 2006. The epidemiology of H5N1 avian influenza in wild birds: why we need better ecological data. Bioscience 56:923-929.

Zakrajsek, E. J., and J. A. Bissonette. 2005. Ranking the risk of wildlife species hazardous to military aircraft. Wildlife Society Bulletin 33:258-264.

Zhang, Y. Q., and J. F. Grassle. 2002. A portal for the ocean biogeographic information system. Oceanologica Acta 25:193-197. 